\title{
Development of Safety Performance using Scoring Technique in Textile Industries
}

\author{
Raj Pradeesh T, Venkumar P, Saravanamani M
}

\begin{abstract}
The objective of the work focus to determine the potential safety factors that directed the triumph of a Human factors safety Management system for Textile workers. The number of accidents among textile workers and the level of responsiveness on problems concerning safety were also determined. The Spinning mills ranged from high noise annoyance areas, rotating machineries and Manual Material handling areas. The sample size was 75 in each sub criteria workers's. From the survey it was found that the most potential safety factor was personal awareness followed closely by statement. Suggestions and recommendations on machinery design and improved safety work practices and measures to improve the efficiency and yield of textile workers were proposed. Management was advised to get their labours response better informed about safety matters. The Investigation survey identify the ineffective management involvement is the main causes of creating safety deficiency inside the textile plants. About 40-80\% of peoples recorded the same reasons to improve the management involvement in all the safety aspects. Very few of the people delivered regarding origin of unsafe acts and condition due to their behaviour of worker inside the workplace related to Human error. This works presents the improved model for management of textile plants in upcoming future investigations.
\end{abstract}

Keywords : safety, factors, behavior, textile, management

\section{INTRODUCTION}

$\mathrm{T}_{\mathrm{e}}$ extile Mill is the major prominent economic segments in virudhunagar district. Behind this manufacturing segments many peoples are working together in that Industrial zone. The study was chosen in virudhunagar district for a famous textile spinning Mills. Although spinning mills causes the noise annoyance inside the plant. Due to this it leads to human hearing loss Tinnitus diseases to the workers. Several risk factors involved in textile industry like physical hazards, Electrical, Fire hazards involved in textile plants. The fig shows the human factor tunnel model to develop the safety practices inside the industries and maintain a safety practices inside the workplace based on the monitoring the workers attitude, behavior e.tc. However several methodologies and risk assessments are available to monitor the risks and hazards

Revised Manuscript Received on December 5, 2019

* Correspondence Author

Raj Pradeesh T*, Department of Mechanical Engineering Kalasalingam Academy of Research and Education, Krishnankoil, India. Email: rajpradeesh29@gmail.com

Venkumar P, Department of Mechanical Engineering Kalasalingam Academy of Research and Education, Krishnankoil, India. Email: p.venkumar@klu.ac.in

Saravanamani M, Department of Mechanical Engineering Kalasalingam Academy of Research and Education, Krishnankoil, India. Email: saravanamani36@gmail.com continued in workplace because many accidents preaches many things based on the lesson learned from that incidents. The Industrial experts innovated the various tool for Risk assessment techniques to completely eliminate the risk from the workplace .In this work completely focus the one to interview methodology instead of risk assessment to mitigate the hazards in textile mills and conduct investigation survey from the workers. This method help to develop the safety practices frequently based on the scoring technique approaches

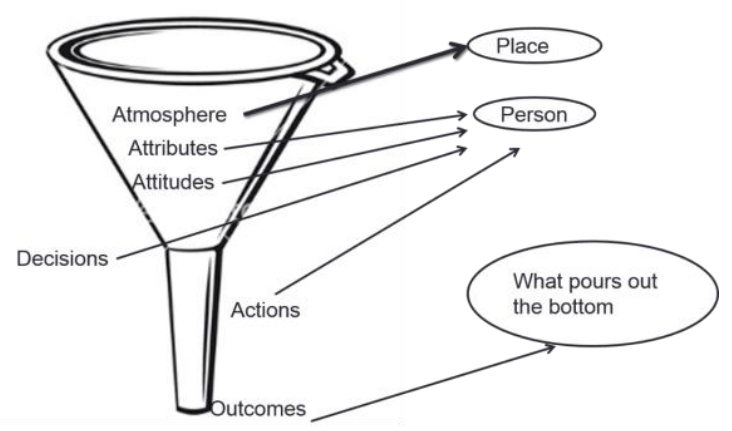

Fig. 1.Human Factors tunnnel model for scoring approach

The humanfcators tunnel model show that the number of inputs given as inputs of various parameters like present areas conditions locate in the textile plants. After that attributes represents number of persons involved in that survey. On the other hand the workers are given their opinion individually based on the presence of mind in 5 point licker scale that comes under the decision of the people and actions that can be taken based on the behaviours.Finally all the results are consolidated and outcomes are listed. Based on the outcomes values the safety practices can able to develop in the required units of the investigation carried out in their corresponding responders sections. The investigation involved a self-investigation to the workers in the way of five-part questionnaire scoring techniques among the workers and interviews with industry experts involved in spinning and Packaging sections. Part 1 of the questionnaire concerned Working hours, Part 2 involved Physical factors , Part 3 about the Management Participation factors, Part 4 preach about the Human behavior factors and Errors in workplace and Part 5 show the self-awareness factors of workers and training undergone in industries was based on industry-accepted safety factor elements. 
The responders is one of the major contribution to this survey and given his/her information regarding the safety violations and management involvement show the ability to enhance and develop the safety cultures in organizations. This work able to given clear description about the workers attitude based on the Human factors tunnel model design by the information as input and sequence of output by the workers.

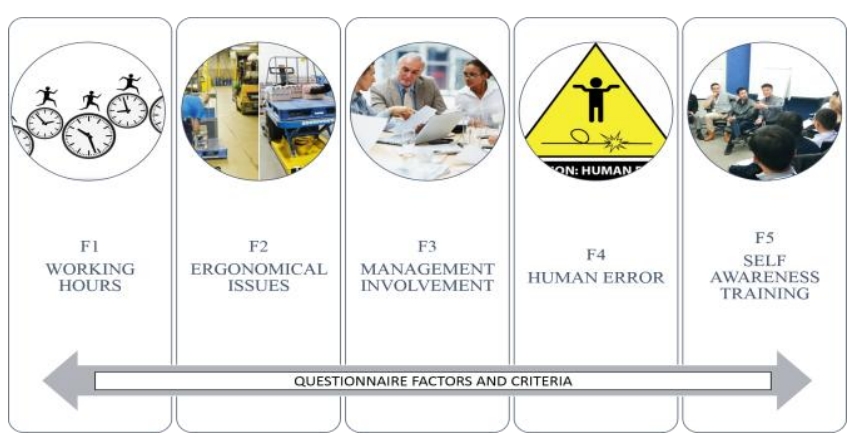

Fig. 2. Categoires of Scoring approach factors and criteria

\section{LITERATURE REVIEW}

[1] Sukran sekar, 2019 conducted a risk assessment for pharmaceutical industry to identify the potential and harmful hazards present inside in industry. In order to bow tie tool was used to identify the hazards and risks level under uncernity conditions in a pharmaceutical industries. The author used the QRA (Quantitative Risk assessment) as a methodology predict the outcomes of the possible parameters.

[2] Gurcanli et al, 2009 analysed the risk level present in a construction sites. The risk assessment was conducted during the work carried out in construction sites with the combination of fuzzy logic. The assessment was used to identify the safety climate present in the appropriate manner. The author concluded amount of risk level present in workplace and able to develop the safety culture inside the construction sites.

[3] W.H. Fung et al, 2010 conducted an investigation study on construction site workers. The authors more focuses on hazards and risk faced by the workers during work time in order to improve the safety culture in construction site. They proposed the RAM (Risk Assessment Model) for construction Industrial experts.

[4] Dong-Chul Seo et al, 2004 conducted the investigation survey on various industries with the reference of various researchers' articles and reviews. In absence of various data's and empirical values the author develop the safety climate and systematic approach in every industry.

[5] Couce-Vieira et al, 2017 frame a structure methodology for incident accident analysis. It is a management approach used to develop the safety practice in workplace. In this analysis the authors used the new innovative methodology for accident and risk analysis in industries.

[6] Abel Pinto et al, 2011 reviewed the risk assessments conducted in construction industries. The author mainly focus the appropriate parameters that have been used for the assessments purpose applied in construction industries. Also the authors discussed the disadvantages of in absence data's used in ORA traditional methods.

[7[O.N. Aneziris et al, 2012 represented the problems encountered in construction work carried out by the workers. Hazard identification conducted by models developed by the authors such as Occupational Risk Model (ORCA) with reference of Workgroup Occupational Risk Model project (WORM), in the Netherlands, for enumerating work-related threat. This methodology evaluates work-related risk of a labors, in addition of several jobs, actions and their corresponding potential threats faced by the workers in workplaces.

[8] Abu Hamja et al, 2019 conducted the serious discussion by revising the current information about the outcome of lean on efficiency and safety in the garment sectors. The final outcomes of this review was to improve the productivity of garment industry while the safety team take care for the improvement in safety culture.

[9] Getnet Abat Tafere et al, 2019 conducted the investigations about the health and safety deficiencies among the industrial workers in industries. The outcomes of this investigation concluded that more number of induction training conducted to the new and current employees in workplaces, higher official give more importance regarding safety development activities carried out in workplace, form a safety committee and arranging the necessary personal protective equipment to the workers that can help to develop the safety follow-ups inside the workplace.

[10] L.B. Andersen et al, 2012 reviewed the effects and manipulating potential issues of safety parameters in industries. The authors finally given suggestions based on the results that the economic problems was one of the major reason did not maintain the safety parameters and the outcomes of safety deficiencies are not properly maintained this leads to the failure of maintain general safety and OHS hazards in appropriate manner.

\section{METHODOLOGY}

This journal uses double-blind review process, which means that both the reviewer (s) and author (s) identities concealed from the reviewers, and vice versa, throughout the review process. All submitted manuscripts are reviewed by three reviewer one from India and rest two from overseas. There should be proper comments of the reviewers for the purpose of acceptance/ rejection. There should be minimum 01 to 02 week time window for it.

\section{A. Interview Questionnaire Approach}

This methodology is one of the qualitative analysis which shows the workers mind attitude as a result of his/her feedback. This method requires one person interview like one person asking questions and others in opposite gives a feedback regarding that questions arise from the interviewer. From this method many advantages are available. No one can shows their face in-front of management official because the interviewer maintain the confidential regarding that opposite person because it shows the reality feedback of workers about their working place information's. In this face to face interview methodology questions are framing full only on working place information's only. So that surveyor or interviewer maintain the confidential and not disclose the workers information .only consolidated results only give to the management for their future investigation surveys. 


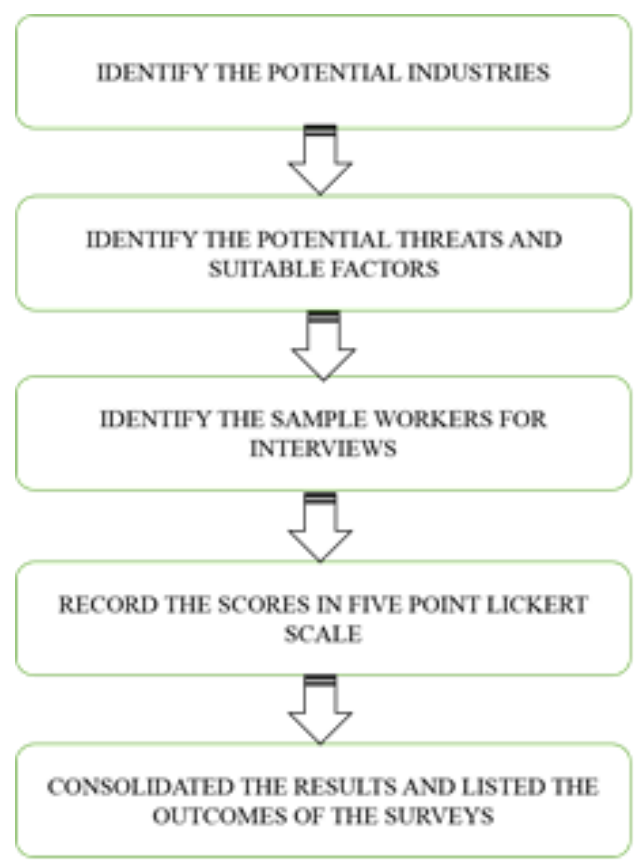

Fig. 3. Flow chart for conducting face to face interviews

\section{B. Scoring Technique approach}

The Scoring approach is the tool used for identify the proper parameters to achieve for our own decision. In these Investigation we segregate the questionnaire based on the suitable parameters and thus used as a choice of 5 point licker scale. The corresponding scales and score values are shown below the table.

TABLE I :5 POINT Licker SCales VALUeS

\begin{tabular}{|c|l|l|}
\hline SNO & CHIOCE SCALES & \multicolumn{1}{c|}{ SCORES } \\
\hline 1 & Agree & 2 \\
\hline 2 & Strongly Agree & 4 \\
\hline 3 & Disagree & 6 \\
\hline 4 & Strongly disagree & 8 \\
\hline 5 & Agree neither nor disagree & 10 \\
\hline
\end{tabular}

In this scoring techniques the factors and criteria are categorized into five different groups based on the Questinarraie framed. The corresponding Questinarraie and criteria are shown in below figure. It shows the corresponding factors represents the parameters related to the criteria focus the appropriate feedback that can be collected from the workers face to face interviews

\section{DATA COLLECTIONS}

Based on their category the score are taken in the above formats. If the Responder give strongly agree means its shows the values of risk is 2 simultaneously for strongly disagree- 4 , Disagree-6, strongly disagree-8, Agree neither nor disagree-10

\section{TABLE I. SAMPLE WORKERS RESPONSES}

\begin{tabular}{|l|l|l|}
\hline \multicolumn{2}{|c|}{ WORKER-1 } \\
\hline SNO & QUESTIONS & $\begin{array}{l}\text { RESPONSE } \\
\text { SCORES }\end{array}$ \\
\hline & $\begin{array}{l}\text { I am Handling Excessive weights at the working } \\
1\end{array}$ & 4 \\
\hline 2 & Hours & 4 \\
\hline
\end{tabular}

\begin{tabular}{|l|l|l|}
\hline 3 & $\begin{array}{l}\text { I have not the Musculo Skeletal Disorder } \\
\text { problems such as back pain in workplace }\end{array}$ & 8 \\
\hline 4 & $\begin{array}{l}\text { I attended the training program about the } \\
\text { ergonomics problems }\end{array}$ & 8 \\
\hline 5 & I use the Proper Tools for Proper Use & 8 \\
\hline 6 & $\begin{array}{l}\text { I am Satisfied with the workplace Situation and } \\
\text { arrangement }\end{array}$ & 8 \\
\hline 7 & $\begin{array}{l}\text { I am feeling causes of Physical discomfort at } \\
\text { workplace }\end{array}$ & 4 \\
\hline 8 & $\begin{array}{l}\text { I am feeling most of an awkward postures to } \\
\text { perform in workplace }\end{array}$ & 6 \\
\hline 9 & $\begin{array}{l}\text { The Various types of lightning is arranged by the } \\
\text { management }\end{array}$ & 8 \\
\hline 10 & $\begin{array}{l}\text { I am feeling the same job during the workplace } \\
\text { same time again and again }\end{array}$ & 10 \\
\hline 11 & $\begin{array}{l}\text { The Various types of ventilation are available at } \\
\text { workplace }\end{array}$ & 8 \\
\hline 12 & $\begin{array}{l}\text { My management is arranging medical } \\
\text { examination regularly }\end{array}$ & 10 \\
\hline 13 & $\begin{array}{l}\text { The Various types of lifts and hoists are available } \\
\text { in my workplace }\end{array}$ & 10 \\
\hline 14 & $\begin{array}{l}\text { My Supervisor is conducting inspection } \\
\text { regularly regarding ergonomics problems }\end{array}$ & 10 \\
\hline 15 & $\begin{array}{l}\text { I have already some biological problems in my } \\
\text { body }\end{array}$ & 8 \\
\hline 16 & $\begin{array}{l}\text { I analyzed and see the incident due to the } \\
\text { phylogical problems. }\end{array}$ & 10 \\
\hline 17 & $\begin{array}{l}\text { I already committed mistake due to absence of } \\
\text { minds in workplace }\end{array}$ & 10 \\
\hline 18 & $\begin{array}{l}\text { I have well knowledge about ergonomics } \\
\text { problems }\end{array}$ & 8 \\
\hline 19 & $\begin{array}{l}\text { My management is well support for workers } \\
\text { Safety and health }\end{array}$ & 10 \\
\hline 20 & I have been working for 8 hours per day \\
\hline
\end{tabular}

In this above table shows the sample responders will response their questionnaire views based on their own thinking related to human factors safety knowledge's. In the mean while take 15 samples were recorded and thus employed in scoring approaches

\section{TABLE II. 15 SAMPLES CONSOLIDATED SCORES}

\begin{tabular}{|l|l|}
\hline WORKERS & TOTAL SCORE \\
\hline WORKER 1 & 148 \\
\hline WORKER 2 & 154 \\
\hline WORKER 3 & 154 \\
\hline WORKER 4 & 160 \\
\hline WORKER 5 & 160 \\
\hline WORKER 6 & 158 \\
\hline WORKER 7 & 154 \\
\hline WORKER 8 & 160 \\
\hline WORKER 9 & 162 \\
\hline WORKER 10 & 154 \\
\hline WORKER 11 & 162 \\
\hline WORKER 12 & 164 \\
\hline WORKER 13 & 154 \\
\hline WORKER 14 & 148 \\
\hline WORKER 15 & 160 \\
\hline
\end{tabular}

Based on their human factors and safety criteria the WORKER Questinarraie is split up into five parameters. Then the data has been analyzed by using the following parameters. 
TABLE III. FACTORS DATA ANALYSED MODEL

\begin{tabular}{|c|c|c|}
\hline SNO & PARAMETERS & QUESTIONNAIRES \\
\hline 1 & WORKING HOURS & $\begin{array}{l}1 . \text { I am Handling Excessive weights } \\
\text { at the working Hours. } \\
2 \text {. I am Working Continuously } \\
\text { Without Break } \\
10 . \text { I am feeling the same job during } \\
\text { the workplace same time again and } \\
\text { again. } \\
20 \text {. I have been working for } 8 \text { hours } \\
\text { per day }\end{array}$ \\
\hline 2 & $\begin{array}{l}\text { ERGONOMICAL } \\
\text { ISSUES }\end{array}$ & $\begin{array}{l}\text { 3. I have not the Musculo Skeletal } \\
\text { Disorder problems such as back pain } \\
\text { in workplace } \\
\text { 7. I am feeling causes of Physical } \\
\text { discomfort at workplace } \\
\text { 8. I am feeling most of an awkward } \\
\text { postures to perform in workplace. } \\
\text { 15. I have already some biological } \\
\text { problems in my body. }\end{array}$ \\
\hline 3 & $\begin{array}{l}\text { MANAGEMENT } \\
\text { INVOLVEMENT }\end{array}$ & $\begin{array}{l}\text { 9. The Various types of lightning is } \\
\text { arranged by the management. } \\
\text { 11. The Various types of ventilation } \\
\text { are available at workplace. } \\
\text { 12. My management is arranging } \\
\text { medical examination regularly. } \\
\text { 13. The Various types of lifts and } \\
\text { hoists are available in my workplace. } \\
\text { 14. My Supervisor is conducting } \\
\text { inspection regularly regarding } \\
\text { ergonomics problems. } \\
\text { 19. My management is well support } \\
\text { for workers Safety and health. }\end{array}$ \\
\hline 4 & HUMAN ERROR & $\begin{array}{l}\text { 16. I analyzed and see the incident } \\
\text { due to the phylogical problems. } \\
\text { 17. I already committed mistake due } \\
\text { to absence of minds in workplace }\end{array}$ \\
\hline 5 & $\begin{array}{l}\text { SELF } \\
\text { AWAARENES } \\
\text { TRAINING }\end{array}$ & $\begin{array}{l}\text { 4. I attended the training program } \\
\text { about the ergonomics problems. } \\
\text { 5. I use the Proper Tools for Proper } \\
\text { Use. } \\
\text { 6. I am Satisfied with the workplace } \\
\text { Situation and arrangement } \\
\text { 18. I have well knowledge about } \\
\text { ergonomics problems. }\end{array}$ \\
\hline
\end{tabular}

TABLE IV. TOTAL CONSOLIDATED FACTOR ANALYSED DATAS

\begin{tabular}{|c|c|c|c|}
\hline SNO & CRETERIAS & WORKERS & SCORES \\
\hline \multirow[t]{15}{*}{1} & \multirow{15}{*}{$\begin{array}{l}\text { WORKING } \\
\text { HOURS }\end{array}$} & WORKER 1 & 22 \\
\hline & & WORKER 2 & 34 \\
\hline & & WORKER 3 & 40 \\
\hline & & WORKER 4 & 38 \\
\hline & & WORKER 5 & 38 \\
\hline & & WORKER 6 & 34 \\
\hline & & WORKER 7 & 38 \\
\hline & & WORKER 8 & 36 \\
\hline & & WORKER 9 & 38 \\
\hline & & WORKER 10 & 32 \\
\hline & & WORKER 11 & 34 \\
\hline & & WORKER 12 & 32 \\
\hline & & WORKER 13 & 38 \\
\hline & & WORKER 14 & 32 \\
\hline & & WORKER 15 & 36 \\
\hline 2 & ERGONOMICAL & WORKER 1 & 22 \\
\hline
\end{tabular}




\begin{tabular}{|l|l|l|}
\hline \multirow{4}{*}{} & WORKER 8 & 32 \\
\cline { 3 - 4 } & WORKER 9 & 34 \\
\cline { 2 - 3 } & WORKER 10 & 28 \\
\hline & WORKER 11 & 36 \\
\hline & WORKER 12 & 40 \\
\hline & WORKER 13 & 34 \\
\hline & WORKER 14 & 26 \\
\hline & WORKER 15 & 34 \\
\hline
\end{tabular}

\section{RESULT AND DISCUSSION}

Finally the management involvement is very low in the ergonomics mitigation problems in textile Industry while compared to the other criteria management involvement is too low like development of workers safety itself as well as ergonomics issues. All though the workers is little bit very much knowledge about self-awareness training and participatory of ergonomical issues also the human error is very low compared with the other criteria.

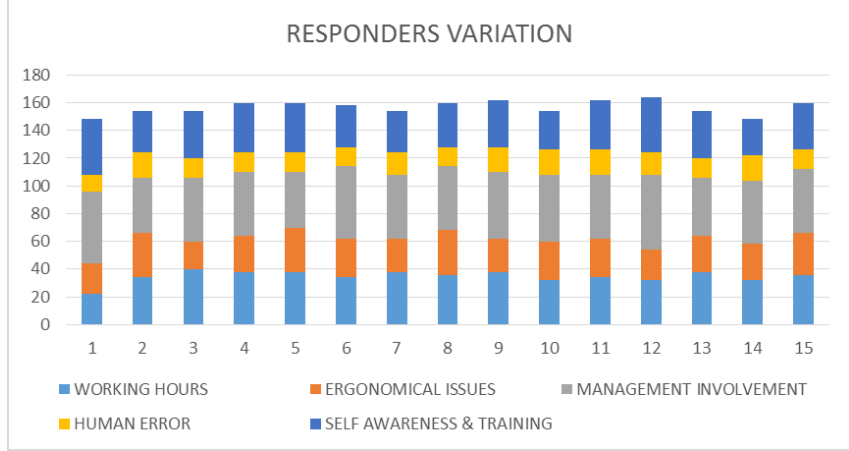

Fig 4 Worker's variation and analysitical approach

\section{CONCLUSION}

The target of this survey was examine the various effect a change in work, which is often found in assembly processes in the textile industry, would have on an individual's responses. The works participation can be included by using the scoring techniques their results were deeply discussed. In future it can be extended for other manufacturing sectors like automobile manufacturing, food manufacturing and various domains of industrial sectors and using a various other mathematical approach even using a simulation technique. Based on the expert's opinion this model can be modified further in future investigation. This model can be used as reference for industrial expert's worked in reputed industrial and research organization

\section{REFERENCES}

1. S.Seker."Analyzing occupational risks of pharmaceutical industry under uncertainty using a Bow-Tie analysis", An International Journal of Optimization and Control: Theories \& Applications (IJOCTA), Vol.9(2),2019, 113-124..

2. G.E. Gürcanli., \& U.Müngen. "An occupational safety risk analysis method at construction sites using fuzzy sets", International Journal of Industrial Ergonomics, Vol. 39(2),2009, 371-387.

3. W.I.Fung., V. W Tam, T. Y Lo \& L. L Lu," Developing a risk assessment model for construction safety. International Journal of Project Management", Vol.28(6), 2010, 593-600.
4. D. C Seo, M. R Torabi, E. H Blair, \& N. T Ellis,” A cross-validation of safety climate scale using confirmatory factor analytic approach". Journal of safety research, Vol.35(4), 2004, 427-445...

5. A Couce-Vieira., D.Rios Insua, \& S. H Houmb. "GIRA: a general model for incident risk analysis". Journal of Risk Research, Vol.22 (2), 2019, 191-208.

6. A.Pinto, I. L Nunes, \& R. A Ribeiro.. "Occupational risk assessment in construction industry-Overview and reflection". Safety science, Vol. 49(5), 2011, 616-624.

7. O.N.Aneziris, E.Topali, \&, I. A Papazoglou. "Occupational risk of building construction". Reliability Engineering \& System Safety, Vol.105, 2012, 36-46.

8. A Hamja, M Maalouf, \& P Hasle, "The effect of lean on occupational health and safety and productivity in the garment industry-a literature review". Production \& Manufacturing Research, Vol.7(1),2019, 316-334.

9. G. A Tafere, G. K Beyera and S. D Wami.. "The effect of organizational and individual factors on health and safety practices: results from a cross-sectional study among manufacturing industrial workers". Journal of Public Health, 2019,1-7.

10. L. B Andersen, D.Häger, S Maberg, M. B Næss, and M Tungland, "The financial crisis in an operational risk management context-A review of causes and influencing factors". Reliability Engineering \& System Safety, Vol.105, 2012,3-12.

\section{AUTHORS PROFILE}

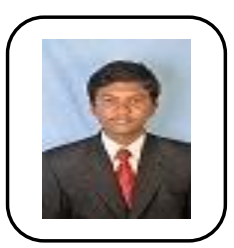

Rajpradeesh T Working as Assistant Professor at Kalasalingam Academy of Research \& Education. His research interest in the domain of Industrial Safety Engineering. He published one SCI Paper in the API Publication.

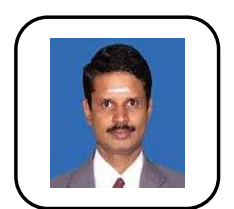

Venkumar $\mathbf{P}$ Working as Senior Professor at Kalasalingam Academy of Research and Education. He contributed more than 10 years in Industrial Engineering domain and published around 39 Research papers.

Saravanamani M Pursue his PG Degree in Industrial Safety Engineering at Kalasalingam Academy of Research and Education-Krishnankoil. 